\title{
Down sendromlu hastalarda kalça sorunları
}

\author{
Hip problems in patients with Down's syndrome
}

\author{
Ali Turgut, Önder Kalenderer
}

İzmir Tepecik Eğitim ve Araştırma Hastanesi, Ortopedi ve Travmatoloji Kliniği, İzmir, Türkiye

\begin{abstract}
Down sendromu (Trizomi 21) insanlarda en sık görülen kromozomal anormalliktir. Bu hastaların çoğu kardiyovasküler cerrahideki gelişmeler öncesi kardiyovasküler nedenlerle kaybedilmekteydiler. Günümüzde bu hastaların yaşam beklentileri uzamıştır. Down sendromlu hastalarda kas iskelet sistemi anormalliklerinin oluşmasının ana mekanizması kas hipotonisi ve bağ gevşekliğidir. Sonuç olarak; üst boyun omurlarında, dizlerde ve kalçalarda instabilite, subluksasyon ve çıkık oluşabilmektedir.
\end{abstract}

Bu hasta grubunda; displazi-subluksasyon ve çıkık, femur başı epifiz kayması ve femur başı avasküler nekrozu gibi kalça problemleri görüldüğü bildirilmiştir. Kalça eklemleri doğumda tipik olarak normal olmakla birlikte, anormal bulgular 2-10 yaş arasında görülmeye başlar. Erişkin hastalarda \%28'e kadar oranda kalça patolojisi oluşabilir. Kalça instabilitesi konservatif veya cerrahi olarak tedavi edilebilir. Anestezi uzmanlarının olası atlanto-aksiyel instabilite konusunda uyarılmaları önerilir; osteotomi uygulanan hastalara kapsül plikasyonu eklenmelidir. Bu hastalarda yara yeri enfeksiyonu normal popülasyona göre daha sık izlenir. Yine bu hasta grubunda femur başı epifiz kayması nedeni ile tedavi edilen hastaların sonuçları da normal popülasyona göre kötüdür. Femur başı epifiz kayması olan hastalarda tiroid bezi disfonksiyonu araştırılmalıdır.

Anahtar sözcülkler: Down sendromu; kalça sorunu; instabilite; laksite
Down's syndrome (Trisomy 21) is the most frequently seen chromosomal abnormality in humans. Before the developments in cardiovascular surgery, most of these patients were dying because of cardiovascular abnormalities; but nowadays, these patients' life-time expectancy is longer. Main mechanisms of musculoskeletal abnormalities that occur in these patients are muscle hypotonia and ligamentous laxity. As a result of these; instability, subluxation and dislocation can occur at upper servical spine, knees and hips.

Hip problems such as; dysplasia-subluxation and dislocation, slipped capital femoral epiphysis and avascular necrosis of the femoral head had been reported in this patient group. Hip joints are typically normal at birth but abnormal findings are seen at 2 to 10 ages. Hip pathology can occur up to $28 \%$ of adult patients. Hip instability can be treated either conservatively or surgically. It is emphasized that; anesthesiologists have to be aware of possible atlanto-axial instability; besides, plication of the hip capsule has to be added to osteotomies. Surgical site infection rates had been reported more than normal in this patient group; the results of treatment of the patients who have slipped capital femoral epiphysis are also worse. Thyroid gland dysfunction has to be investigated in patients with slipped capital femoral epiphysis.

Key words: Down's syndrome; hip problem; instability; laxity

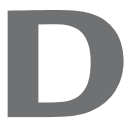
own sendromu (DS), diğer adı ile trizomi 21 insanlarda en sık rastlanan otozomal kromozom anomalisidir. Bu sendromun klinik yansıması; mental retardasyon, yüz anomalileri, konjenital kardiyak-abdominal hastalıklar ve bir takım dikkat çekici ortopedik deformitelerdir. ${ }^{[1,2]}$ DS'li hastalar 1940'lı yıllarda özellikle kardiyak nedenler ile kaybedilmekteydi. Cerrahi ve teknoloji alanlarındaki gelişmeler sayesinde DS'li hastaların yaşam beklentileri oldukça uzamıştır. ${ }^{[3-5]} \mathrm{Bu}$ hastalarda yaşam süresinin uzaması ile birlikte kas-iskelet sistemi ile ilgili hastalıkların görülme olasılığı da artmıştır.

DS'li hastalarda kas iskelet sistemi hastalıklarının oluşmasının temel nedeni bu hastalarda görülen bağ gevşekliği ve kas hipotonisidir. Bunların sonucunda; boyun omurları, diz ve kalçalarda instabilite, subluksasyon ve çıkık oluşabilir (Şekil 1,2$) \cdot{ }^{[2,6,7]}$

- İletişim adresi: Doç. Dr. Önder Kalenderer, İzmir Tepecik Eğitim ve Araştırma Hastanesi Ortopedi ve Travmatoloji Kliniği, Gaziler Cad. No: 468, Yenişehir, İzmir, Türkiye Tel: 0232 - 4696969 e-posta: okalenderer@yahoo.com

- Geliş tarihi: 3 Eylül 2014 Kabul tarihi: 3 Eylül 2014 
Bu hastaların pelvis grafileri değerlendirildiğinde; genel olarak, iliak kanatların genişlediği, asetabulumun derinleştiği, asetabular çatının horizontalleştiği, femoral anteversiyon açısının orta derecede artmış olduğu, femur boyun-cisim açısının ise normal olduğu görülür. ${ }^{[2,7]}$ Her ne kadar bu sayılan bulgular kalça ekleminin stabil olacağını düşündürmekte ise de, önceden de bahsedildiği gibi, bu hastaların bağ gevşekliği ve hipotoniye sahip olmaları instabilite oluşturabilir.

Bu hastalarda kalça eklemi ile ilgili görülebilecek ve önceden bildirilmiş ortopedik hastalıklar; kalça displazisi-çıkığı, femur başı epifız kayması ve femur başı avasküler nekrozudur. Bu hastalıklardan en sık rastlanılanı displazi ve çıkıktır. Kalça çıkığı görülme sıklığı yaklaşık \%5 olarak bildirilir. ${ }^{[8]}$ Bu hastaların kalçaları tipik olarak doğumda normaldir; ancak, 2-10 yaş arasında kalça sorunları görülmeye başlar. ${ }^{[3-5]}$ Çocukluk çağında kalça instabilitesi \%1,3-7 arasında bildirilmekle beraber erişkin hastalarda \%28 oranında kalça patolojilerine rastlanır. ${ }^{[9]}$

DS'li hastalarda görülen kalça çıkığı, Bennet ve arkadaşları tarafından evrelendirilerek ele alınmıştır. ${ }^{[10]}$ Buna göre:

\section{BAŞLANGIÇ FAZI}

Kalçalar iki yaşına kadar stabil ancak hipermobildir. Bu yüzden bu gruptaki hastaların yürümeleri de genellikle gecikir. Pelvis grafisindeki bulgular karakteristiktir; iliak kanatlar geniş, asetabulum normalden daha derindir. Bu süreçte nadiren doğuştan kalça çıkığına rastlanır ve klasik tedavi yöntemleri genellikle başarılı olur.

\section{ÇIKIK FAZI}

\section{Habitüel Çıkık}

íki-on yaş arası kalça eklemi, travma olmadan spontan olarak çıkar ve kendiliğinden redükte olur. Bu dönemde çocuklar; kalçada klik sesi duyulması, artan topallama veya kalçada boşalma hissi nedeni ile hekime getirilirler.

\section{Akut Çıkık}

Yedi-sekiz yaşından sonra çocuklar; ani artan topallama ve aktivite azalması nedenleri ile başvururlar. Ağrı, esas yakınma değildir. Kalça klinik olarak çıkıktır, ancak anestezi altında kolayca redükte edilir.

\section{SUBLUKSASYON FAZI}

Bu gruptaki hastalarda kalçanın konsantrik olarak redüksiyonu zordur ve ilerleyici asetabular displazi gelişir.

\section{SABIT FAZ}

Yirmili yaşlarda, eğer önceden tedavi edilmezse sabit kalça çıkığı oluşur. Tüm hastalar belirgin topallama olmasına karşın herhangi bir yardımcı cihaz olmadan yürüyebilirler. Çok azında ağrı kesici kullanma ihtiyacı gerektirmeyen kalça ağrısı bulunabilir. Röntgenlerde iliak kalça çıkığı (yükssekte kalça çıkı̆̆ı), yanlış asetabulum (neokotil) ve asetabular displazi izlenir.

Bu hasta grubunda kalça çıkığı tedavisi ile ilgili literatür incelendiğinde, en geniş seri yine Bennet ve arkadaşlarına aittir. ${ }^{[10]}$ On sekiz hastanın 26 çıkık kalçası yazarlar tarafından tedavi edilmiştir. Buna göre:

\section{AMELIYATSIZ TEDAVI}

Beş kalçaya kapalı redüksiyon ve pelvi-pedal alçı (PPA) uygulanmıştır. Birisinde tedaviden iki ay, diğerinde yedi yıl sonra olmak üzere kalıcı subluksasyon olduğu izlenmiştir. Bir diğer kalçada, alçı içindeyken üç ay sonunda tekrar çıkık oluşmuş ve innominat osteotomi ile tedavi edilmiştir. Bir kalça, üç ayrı kez çıkmış ve hepsinde kapalı redüksiyon ve alçı uygulanmıştır. Son alçıdan üç yıl sonra kalça stabil olarak değerlendirilmiştir. Son kalça, bir yıl sonunda stabil olarak değerlendirilmiş ancak sonradan hasta takipten çıkmıştır.

\section{AMELIYATLA TEDAVi}

Önceden varus osteotomisi yapılmış bir kalçaya ve bir diğer kalçaya kapsüler plikasyon yapılmış ve bu kalçalar sırası ile iki ve yedi yıl sonra stabil olarak değerlendirilmiştir. Femoral osteotomi beraberinde kapsüler plikasyon yapılan hastaların hepsinde (üç hasta), takiplerde kalçalar stabil olarak değerlendirilmiştir. Innominat osteotomi ve kapsüler plikasyon uygulanan dört hastada (üçü Salter, biri Sutherland), Salter osteotomisi yapılan hastalarda sonuç iyi iken Sutherland osteotomisi yapılan hastada ilerleyici subluksasyon ve dejeneratif eklem hastalığı ile karşılaşılmıştır. Kapsüler plikasyon yapılmaksızın femoral-iliak osteotomi uygulanan hastalarda genel olarak kötü sonuçlarla karşılaşılmıştır. İki taraflı ağrılı sabit çıkığı mevcut olan bir hastada, Schanz osteotomisi ile iyi klinik sonuç elde edilmiştir. En iyi ihtimalle \%19 hastada yara enfeksiyonu ile karşılaşılmıştır. Yazarlar çıkarım olarak; bu hasta grubunun yarısında tedavinin başarılı olduğunu ancak enfeksiyon olasılığının da azımsanmayacak oranda fazla olduğunu belirtmişlerdir. Kliniğimizde femoral osteotomi ve kapsüler plikasyon ile tedavi edilmiş olan olgu Şekil 3'te, femoral osteotomi-iliak ostotomi ve kapsüler plikasyon ile tedavi edilmiş olan olgu da Şekil 4'te gösterilmiştir. 


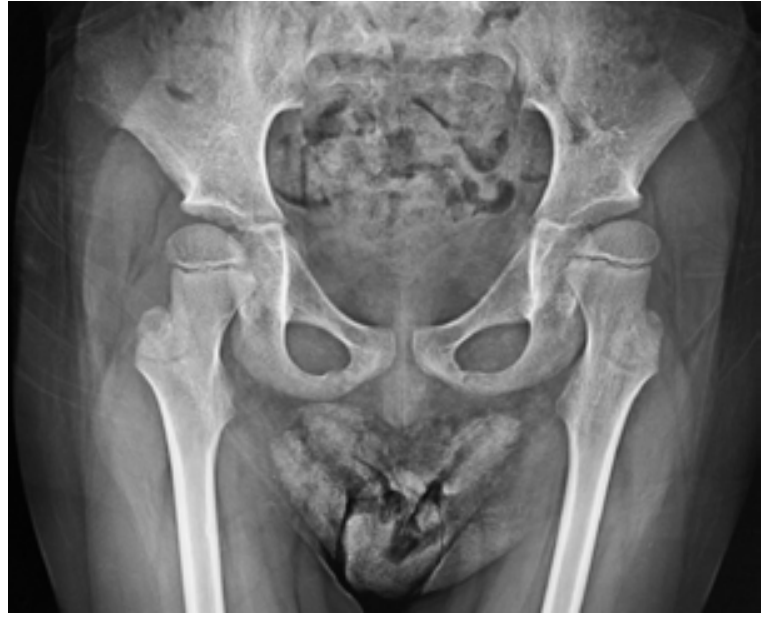

Şekil 1. İki taraflı coxa valga ve femoral anteverisyon artışı olan dokuz yaşındaki Down sendromlu kız hastanın pelvis ön-arka grafisi.

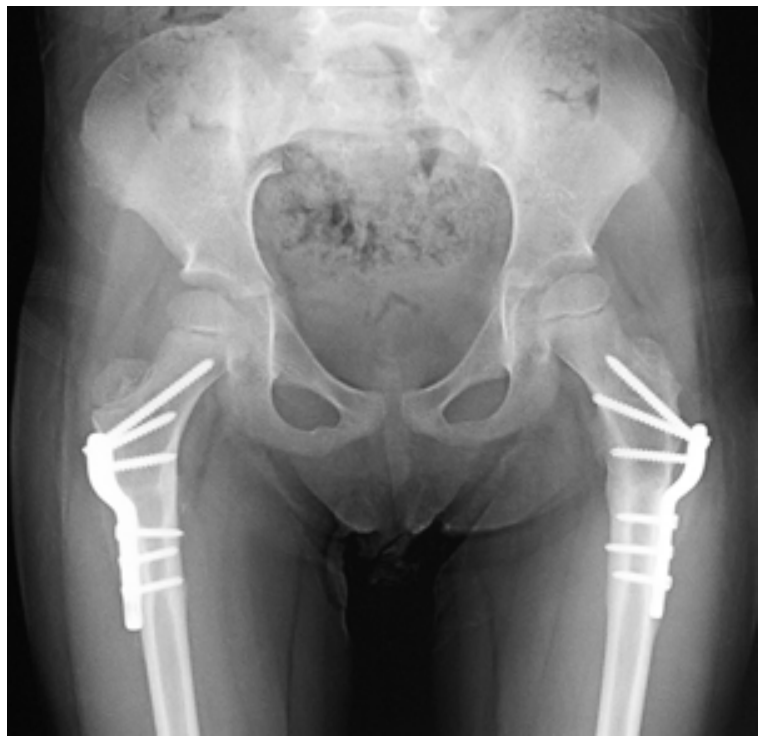

Şekil 3. Varizasyon, derotasyon ve çocuk kalça plak-vida ile tespit sonrası kapsüler plikasyon uygulanan hastanın pelvis ön-arka grafisi

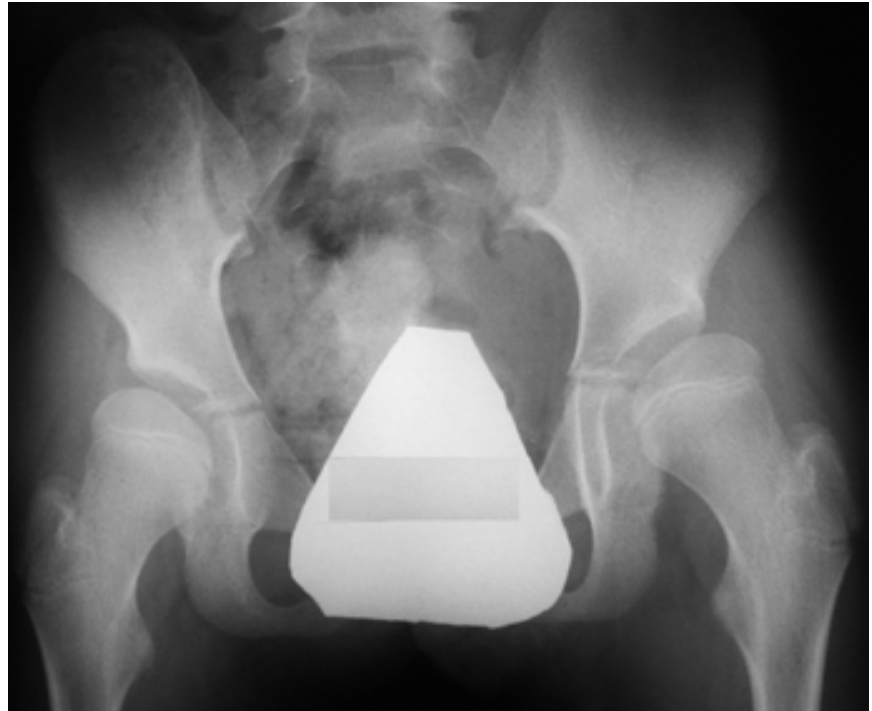

Şekil 2. Sol sublukse, iki taraflı coxa valgalı 11 yaşında Down sendromlu olgu.

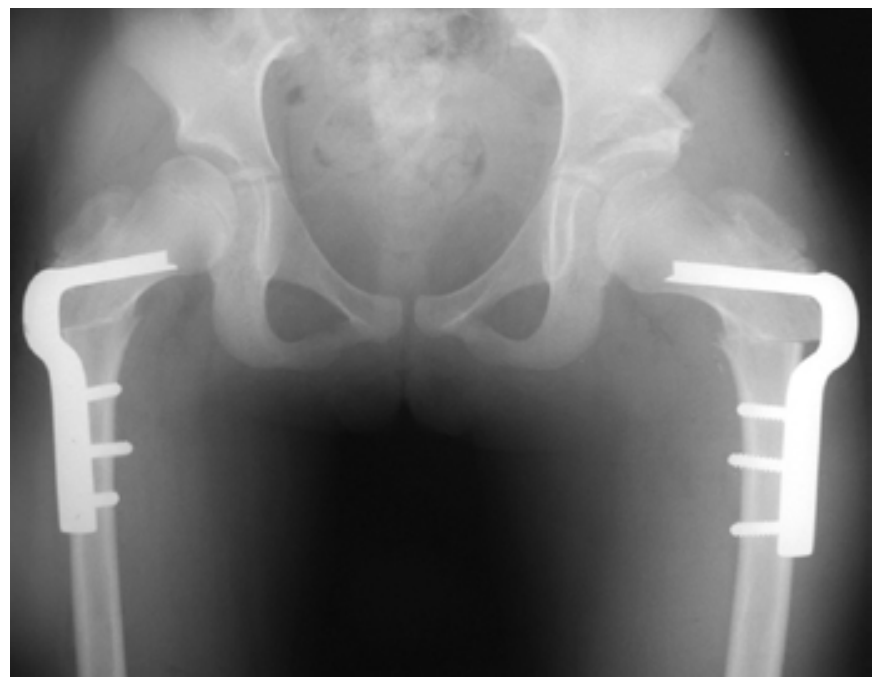

Şekil 4. İki tarafa femoral derotasyon ve varizasyon osteotomisi ve sola Dega osteotomisi sonrası kapsüler plikasyon uygulanan hastanın her iki kalça ön-arka grafisi.

aşılması için komponentlerin valgusta yerleştirilmesi, hatta uyumsuz hastalarda çıkık ihtimalinin aşılması için kilitli asetabular insert kullanılması bile önerilmiştir. ${ }^{[11,13]} \mathrm{Bu}$ hastalarda asetabular retroversiyonda artış ve asetabulum arka duvarının yetmezliği olabileceği unutulmamalıdır. ${ }^{[14]}$

Literatürde, DS'li 17 hastada femur başı epifiz kayması (FBEK) geliştiği bildirilmiştir. ${ }^{[15-19]}$ Bu hastaların 11 'inde avasküler nekroz gelişmiştir (\%64,7). Avasküler nekroz gelişen hastaların dördü stabil tiptir $(\% 36,4)$. Bu oranlar diğer FBEK sonuçlarından oldukça farklıdır. 
DS'li hastalarda görülen FBEK'nin diğer hastalardaki FBEK'ye göre daha çok komplikasyonlara açık olduğu söylenebilir.

Sonuç olarak DS'li bir hastanın kalça hastalıklarını tedavi ederken bir ortopedi hekiminin dikkat etmesi gerekenler aşağıdaki gibi özetlenebilir:

- Bu hastalar ameliyat edilecekler ise atlanto-aksiyel instabilite konusunda anestezi ve reanimasyon birimi uyarılmalıdır.

- Kalça çıkığı genellikle iki yaş sonrası oluşmaktadır; iskelet matüritesi oluştuğunda stabil olan bir kalça bile sonraki yıllarda instabil hale gelebilmektedir. Bu hastalar kalça instabilitesi açısından takip edilmelidir.

- Kalça çıkığı tedavisi için ameliyat yapılıyorsa, osteotomilere kapsül plikasyonu mutlaka eklenmelidir.

- Ameliyat edilen hastalarda, yara yeri enfeksiyonu gelişme olasılı̆̆ının diğer hasta gruplarına göre daha fazla olduğu bilinmelidir.

- Femur başı epifiz kayması olan hastaların sonuçlarının kötü olabileceği bilinmeli ve bu hastalarda mutlaka tiroid bezi fonksiyon bozukluğu olup olmadığı araştırılmalıdır.

\section{KAYNAKLAR}

1. Mann DM. Alzheimer's disease and Down's syndrome. Histopathology 1988;13(2):125-37.

2. Kriss VM. Down syndrome: imaging of multiorgan involvement. Clin Pediatr (Phila) 1999;38(8):441-9.

3. Penrose LS. The incidence of mongolism in the general population. J Ment Sci 1949;95(400):685-8.

4. Bittles $\mathrm{AH}$, Glasson EJ. Clinical, social, and ethical implications of changing life expectancy in Down syndrome. Dev Med Child Neurol 2004;46(4):282-6.

5. Janicki MP, Dalton AJ, Henderson CM, Davidson PW. Mortality and morbidity among older adults with intellectual disability: health services considerations. Disabil Rehabil 1999;21(5-6):284-94.
6. Nance WE, Engel E. Human cytogenetics: a brief review and presentation of new findings. J Bone Joint Surg Am 1967;49(7):1436-54.

7. Shaw ED, Beals RK. The hip joint in Down's syndrome. A study of its structure and associated disease. Clin Orthop Relat Res 1992;(278):101-7.

8. Herring JA, editor. In: Tachdjian's Pediatric Orthopaedics, 3rd ed. Chapter 30. Philadelphia: W. B. Saunders Company; 2002. p.1621-3.

9. Caird MS, Wills BP, Dormans JP. Down syndrome in children: the role of the orthopaedic surgeon. J Am Acad Orthop Surg 2006;14(11):610-9.

10. Bennet GC, Rang M, Roye DP, Aprin H. Dislocation of the hip in Trisomy 21. J Bone Joint Surg Br 1982;64 (3):289-94.

11. Taylor DW, Macdonald MP, Kosashvili Y, Gross AE. Total hip arthroplasty to treat congenital musculoskeletal abnormalities in the juvenile Down Syndrome hip: review of literature with case. J Pediatr Orthop B 2012;21(3):235-9. CrossRef

12. Kioschos M, Shaw ED, Beals RK. Total hip arthroplasty in patients with Down's syndrome. J Bone Joint Surg Br) 1999;81(3):436-9.

13. Skoff HD, Keggi K. Total hip replacement in Down's syndrome. Orthopedics 1987;10(3):485-9.

14. Woolf SK, Gross RH. Posterior acetabular wall deficiency in Down syndrome. J Pediatr Orthop 2003:23(6):708-13.

15. Stack RE, Peterson LF. Slipped capital femoral epiphysis and Down's disease. Clin Orthop Relat Res 1966;48:111-7.

16. Diamond LS, Lynne D, Sigman B. Orthopedic disorders in patients with Down's syndrome. Orthop Clin North Am 1981;12(1):57-71.

17. Makley JT, Sligar W. Orthopaedic surgery in Down's syndrome. Orthop Trans 1979;3:115.

18. Shaw DE, Beals RK. The hip joint in Down's syndrome. A study of its structure and associated disease. Clin Orthop Relat Res 1992;(278):101-7.

19. Dietz FR, Albanese SA, Katz DA, Dobbs MB, Salamon PB, Schoenecker PL, Sussman MD. Slipped capital femoral epiphysis in down syndrome. J Pediatr Orthop 2004;24(5):508-13. 